\title{
Effect of Geometric Swirl Number of Discharge Plasma Catalyzer on Green Monopropellant Reaction Characteristics
}

\author{
By Asato WADA, ${ }^{1)}$ Toshiaki IIZUKA, ${ }^{2)}$ Takahiro ShINDO, ${ }^{1)}$ Hiroshi MAEDA, ${ }^{1)}$ \\ Hiroki WATANABE, ${ }^{1)}$ and Haruki TAKEGAHARA ${ }^{1)}$ \\ ${ }^{1)}$ Department of Aerospace Engineering, Tokyo Metropolitan University, Tokyo, Japan \\ ${ }^{2)}$ Department of Mechanical Engineering, National Institute of Technology, Oyama College, Tochigi, Japan
}

(Received July 30th, 2015)

\begin{abstract}
A new reaction system that uses discharge plasma of noble gas has been proposed as a substitute for the conventional solid catalyst in a reaction control system (RCS) thruster. The propellant of the thruster is a hydroxyl ammonium nitrate (HAN)-based monopropellant instead of the usual hydrazine. The proposed reaction system is a discharge plasma catalyzer (DPC) system, and a laboratory model (LM) has been developed. The DPC-LM is expected to enhance combustion via ion-molecule and radical-molecule reactions from the discharge plasma, and to enable cold-start operation. The objective of this study is to experimentally evaluate the effects of characteristics of the discharge plasma on the propellant reaction characteristics of the DPC-LM by inducing different swirl gas flow patterns, such as by varying the geometric swirl number. The plasma characteristics are evaluated in terms of the success rate of propellant reaction and the reaction delay time. The continuity of the exhaust flame was confirmed for argon gas mass flow rates from 0.125 to $0.175 \mathrm{~g} / \mathrm{s}$ and an SHP163 mass flow rate of $0.3 \mathrm{~g} / \mathrm{s}$ with higher geometric swirl numbers. In addition, it was found that higher geometric swirl numbers reduced the reaction delay time.
\end{abstract}

Key Words: RCS Thruster, Green Monopropellant, Discharge Plasma, Ignition System, Swirl Injector

\section{Nomenclature}

$\begin{array}{cll}R & : \text { radius } \\ A & : & \text { area } \\ n & : & \text { orifice number } \\ V & : & \text { discharge voltage } \\ I & : & \text { discharge current } \\ T & : & \text { time of the phase } \\ \Delta t & : & \text { data sampling rate } \\ I s p & : & \text { specific impulse } \\ \text { Subscripts } & & \\ c & : & \text { central hole } \\ o & : & \text { orifice } \\ i & : & \text { initial } \\ f & : & \text { final }\end{array}$

\section{Introduction}

Since the late $1990 \mathrm{~s}$, replacements of conventional hydrazine have been continuously developed in the United States, Europe, and Asia. ${ }^{1-4)}$ These replacements have been called "green monopropellants" because they have lower toxicities than conventional hydrazine. The lower toxicities of these propellants provides the additional advantage of lower costs from the development phase through to pre-launch phases. ${ }^{3,6)}$ In Japan, one green monopropellant, called SHP163, has been developed by the Japan Aerospace Exploration Agency (JAXA) and Mitsubishi Heavy Industries (MHI).
SHP163 is a liquid mixture of HAN (hydroxyl ammonium nitrate, $\mathrm{NH}_{3} \mathrm{OHNO}_{3}$ ) / ammonium nitrate / water / methanol (= 73.6 / 3.9 / 6.2 / 16.3 by weight percentages $).{ }^{3-5)}$ This green monopropellant is storable as liquid under standard atmospheric conditions and has a higher performance (density-Isp) than hydrazine; thus, the mass of the propulsion system can be reduced at the same delta-V. ${ }^{7,8)}$ However, when employing green monopropellants in reaction control system (RCS) thrusters, there are some technical problems in environments with higher operating temperatures and atmosphere oxidation that conventional solid catalysts significantly reduce. ${ }^{9,10)}$ Conventional solid catalysts do not have these advantages. To solve these problems, two approaches can be considered: improving the performance of conventional solid catalysts or developing a new reaction system as a substitute for the catalyst. An advanced solid catalyst, called LCH-240, has been developed by Aerojet-Rocketdyne. ${ }^{11)}$ This solid catalyst is more resistant to the temperature and oxidation level of the atmosphere.

We use an alternative reaction system, based on focusing discharge plasma, in our laboratory. An reaction system that uses discharge plasma of swirling noble gas, called the discharge plasma catalyzer (DPC), has been proposed previously. ${ }^{12,13)}$ This system is able to operate without preheating, and is expected to enhance combustion through ion-molecule and radical-molecule reactions from the discharge plasma. The reaction system allows for plasma-induced combustion of a green monopropellant. ${ }^{12-14)}$ 
DPC is solid-catalyst-free and has a power consumption of about $300 \mathrm{~W}$ for green propellant reaction. ${ }^{12,13)}$ Therefore, the power consumption of DPC during reaction is lower than that of any other system so far. ${ }^{14)}$

In our previous study, green propellant reaction was achieved using discharge plasma. ${ }^{13)}$ Additionally, it was confirmed that the propellant reaction characteristics are strongly dependent on the discharge plasma distribution prior to supplying the propellant into the discharge zone. ${ }^{12)}$ In contrast, the previous DPC required significant power consumption when used as the reaction system of an RCS thruster. In addition, the swirl strength of the noble gas (argon gas) during plasma generation results in multiple ignitions of the propellant, but this is not well understood. To evaluate the effects of this swirl strength of the argon gas on the plasma distribution and propellant reaction, performance improvement is necessary, such as a reduction in the power consumption and an improvement in the successful reaction rate.

In this paper, the basic propellant reaction characteristics are discussed in terms of the conditions that induce successful propellant reaction and the associated propellant reaction probability (also known as multiple propellant ignition), power consumption, and reaction delay time (also known as ignition delay time). The effects of the geometric swirl number (swirl strength) and argon gas flow rate on these basic reaction characteristics are experimentally evaluated.

\section{Overview of the Discharge Plasma Catalyzer with a Swirl Injector and Evaluation Criteria}

\subsection{Discharge plasma catalyzer with a swirl injector}

Figure 1 shows a cross-sectional view of a laboratory model of the discharge plasma catalyzer (DPC-LM), with a swirl injector supplying the argon gas. A liquid propellant injector is located upstream of the swirl injector. The system also comprises outer housings both upstream and downstream, insulators, and electrodes (cathode and anode). The outer housings and swirl injector are made of polycarbonate material, the electrodes of stainless steel, and the insulators of alumina ceramic.

The schematics of the swirl injector for the various geometric swirl numbers are shown in Fig. 2. The swirl injectors are characterized by the geometric swirl number $S_{g}$. The geometric swirl number determines the angular momentum ratios of the argon gas using the geometry of the swirl injector, such as the orifice and central hole dimensions. Neglecting the viscous force of the argon gas, the geometric swirl number can be defined using only geometrical parameters: $^{15)}$

$$
S_{g} \equiv \frac{P_{\phi}}{P_{c} R_{c}}=\frac{\left(R_{c}-R_{o}\right) A_{c}}{n R_{c} A_{o}},
$$

where $P_{\phi}$ is the angular momentum in the tangential direction and $P_{c}$ is the momentum of the central hole. $R_{c}$ and $R_{o}$ are the radii of the central hole and orifice, $A_{c}$ and $A_{o}$ are the areas of the central hole and orifice, and $n$ is the orifice number. In this study, the swirl strength of argon gas was varied using the geometric swirl number of the swirl injector. Four swirl injectors were prepared to evaluate the effect of the geometric swirl number, for values of $0,3.4,6.7$, and 13.4. A geometric swirl number of 0 has a non-swirled flow field and the other geometric swirl numbers have a swirled flow field, as shown in Fig. 3. The manifold is filled with argon gas, and the gas is supplied through an orifice to the discharge zone, a central hole with a diameter of $4.2 \mathrm{~mm}$. The orifice has a diameter of $1.0 \mathrm{~mm}$.

An experimental apparatus used for static firing tests is shown in Fig. 4. The experimental apparatus consists of the DPC-LM, a gas supply system, a propellant supply system, and a DC power supply. All of the static firing tests were conducted inside a vacuum chamber to ensure safety under atmospheric conditions. The gas supply system consists of an argon gas tank and a solenoid valve (CKD AB41-02-3/AB31-02-2). The argon gas mass flow rate is controlled by the upstream pressure from the argon gas tank. The propellant supply system is a pressure-fed system. The

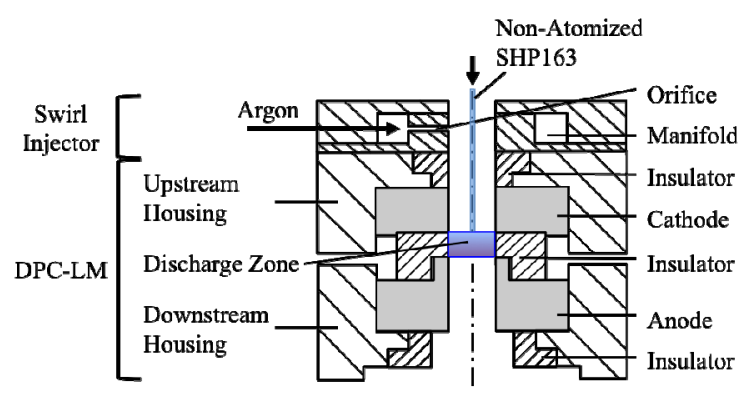

Fig. 1. Overview of the DPC-LM with the swirl injector.

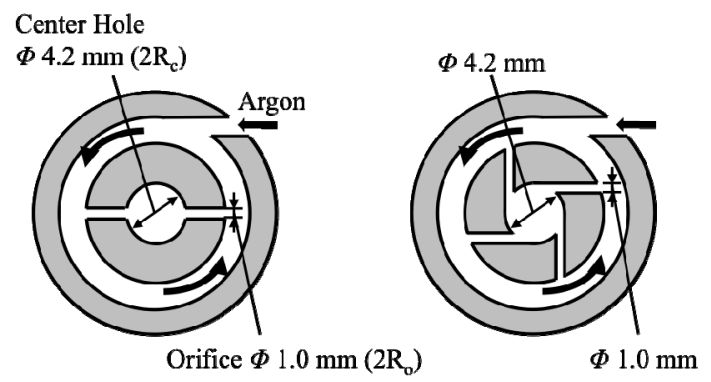

(a) Geometric Swirl Number 0

(b) Geometric Swirl Number 3.4
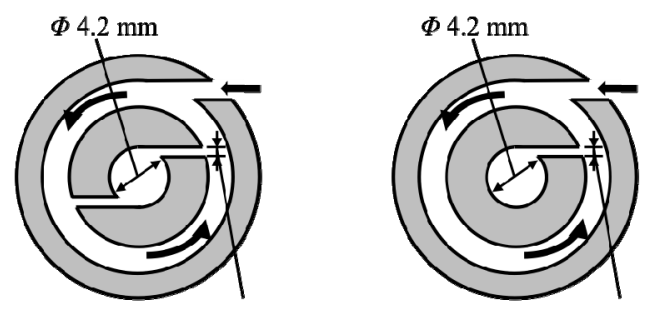

$1.0 \mathrm{~mm}$

$\Phi 1.0 \mathrm{~mm}$

$\begin{array}{lll}\text { (c) Geometric Swirl Number } 6.7 & \text { (d) Geometric Swirl Number } 13.4\end{array}$

Fig. 2. Schematics of the swirl injector with geometric swirl numbers of (a) 0, (b) 3.4, (c) 6.7, and (d) 13.4 - top-down view. 
supply system consists of a nitrogen gas tank, a propellant tank, a non-atomized propellant injector (LEE: INZA4710975H), and a propellant valve (LEE: INKX0514300A-A). The propellant mass flow rate is adjusted using the pressure of the pressurant gas (nitrogen gas). The DC power supply (NISTAC: HV-2K10) was attached outside the vacuum chamber. The input power supply was set with the following conditions: a maximum voltage of $2.0 \mathrm{kV}$ and a current limit of $0.8 \mathrm{~A}$. The discharge voltage and current waveforms were measured with a high-voltage probe (Tektronix: P6015A) and a current probe (HIOKI: 9274), respectively. To evaluate the exhaust plume, the static firing tests were recorded by video camera through the window of the vacuum chamber. In a different experiment, the discharge plasma distribution inside the discharge zone was observed downstream of the DPC-LM using a camera.

The SHP163 mass flow rate of a $1 \mathrm{~N}$-class RCS thruster is about $0.3 \mathrm{~g} / \mathrm{s}$. In this study, the mass flow rate of SHP163 is fixed at $0.3 \mathrm{~g} / \mathrm{s}( \pm 0.03 \mathrm{~g} / \mathrm{s})$, and the mass flow rate of argon gas is varied from 0.125 to $0.175 \mathrm{~g} / \mathrm{s}$.

\subsection{Propellant reaction phase}

Figure 5 shows an illustration of the propellant reaction process. In Phase 1, the argon gas valve, as shown in Fig. 3, is opened, allowing argon gas to flow into the discharge zone through the swirl injector. In Phase 2, the DC power supply is turned on. An intense electric filed is formed between the cathode and anode, and then discharge plasma is generated from ionized argon gas. In Phase 3, the propellant valve is opened. The propellant is ignited when it comes into contact

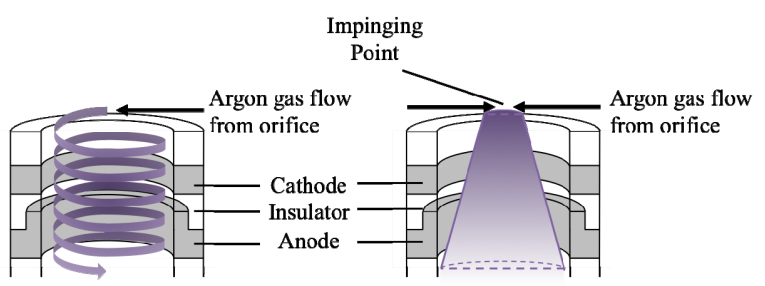

(a) Swirl flow

(b) Non-swirl flow

Fig. 3. Conceptual views of (a) swirled flow and (b) non-swirled flow.

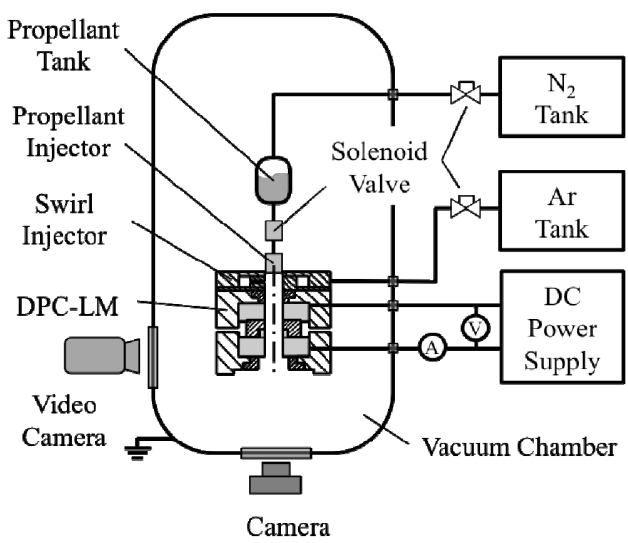

Fig. 4. Overview of the experimental apparatus. with the discharge plasma.

\subsection{Evaluation criteria}

Figure 6 shows a photograph of three reaction categories, stable, unstable, and failed reaction. Stable reaction is defined as the continuity of the exhaust flame. Unstable reaction indicates discontinuity of the exhaust flame. Failed reaction indicates no exhaust plume, and the emission of unreacted propellant.

The instantaneous discharge voltage $V_{(t)}$ and current $I_{(t)}$ are measured using high voltage and current probes, respectively. The following equation is used for calculating the power consumption $P$.

$$
P=\frac{1}{t_{f}-t_{i}} \sum_{t_{i}}^{t_{f}} V_{(t)} I_{(t)} \Delta t
$$

Here, $t_{\mathrm{i}}$ and $t_{\mathrm{f}}$ are the initial and final times of each phase, respectively, and $\Delta t$ is the data sampling rate of $1.0 \mathrm{~ms}$.

\section{Experimental Results}

\subsection{Propellant reaction probability}

First, SHP163 was successfully reacted without any failed reactions under these experimental conditions with geometric swirl numbers 0, 6.7, and 13.4. However, for a geometric swirl number of 3.4, some failed cases were observed,

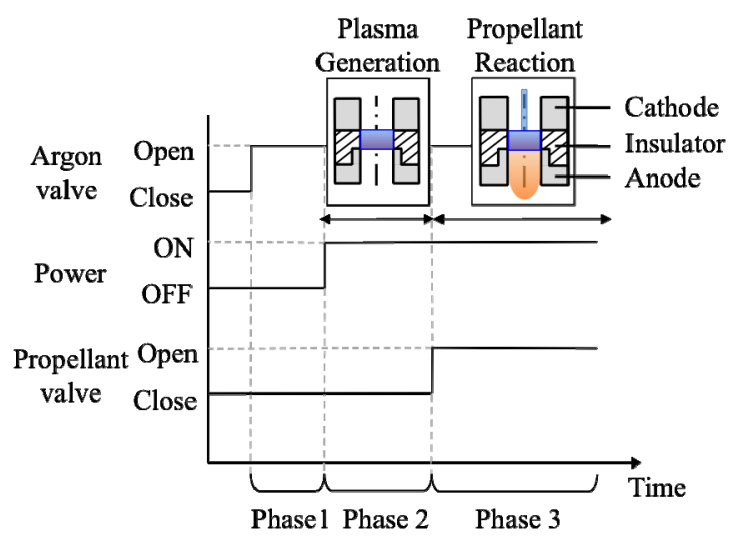

Fig. 5. Propellant reaction phase.

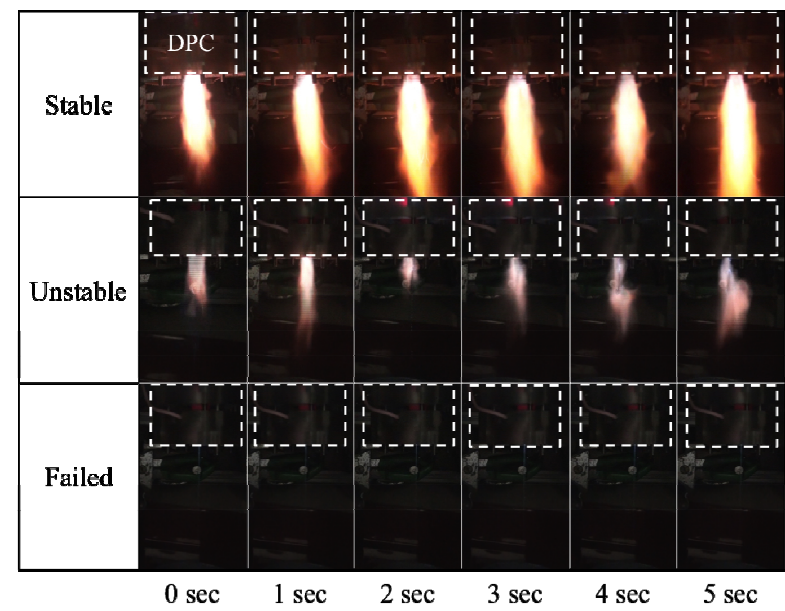

Fig. 6. Images of the three categories of reaction. 
seemingly because of the weak swirl strength. After the reaction of the propellant, some cases (e.g., with a swirl number of 0 at an argon mass flow rate of $0.150 \mathrm{~g} / \mathrm{s}$ ) resulted in discontinuity of the exhaust flame. In the unstable reaction cases, it seems that the propellant reaction may be periodic during Phase 3.

Figure 7 shows the effect of the geometric swirl number on the ratio of continuous propellant reaction and power consumption at Phase 3. The static firing tests were conducted ten times for each argon gas mass flow rate and geometric swirl number. In all cases under our conditions, with swirl numbers $0,6.7$, and 13.4 and for all argon mass flow rates, there were no failed reactions. In the case of a geometric swirl number of 3.4, the propellant reaction became more unstable and reaction failed. Thus, it seems that the lower swirl strength induces flame instability at the discharge zone in the case of swirling argon gas.

The power consumption was varied approximately from $260 \mathrm{~W}$ to $300 \mathrm{~W}$ with successful reaction under our experimental conditions, and it was confirmed that the power consumption is not significantly affected by the swirl strength.

\subsection{Discharge plasma distribution at phase 2}

In the previous section, the relation between the propellant reaction and geometric swirl number was discussed. In this

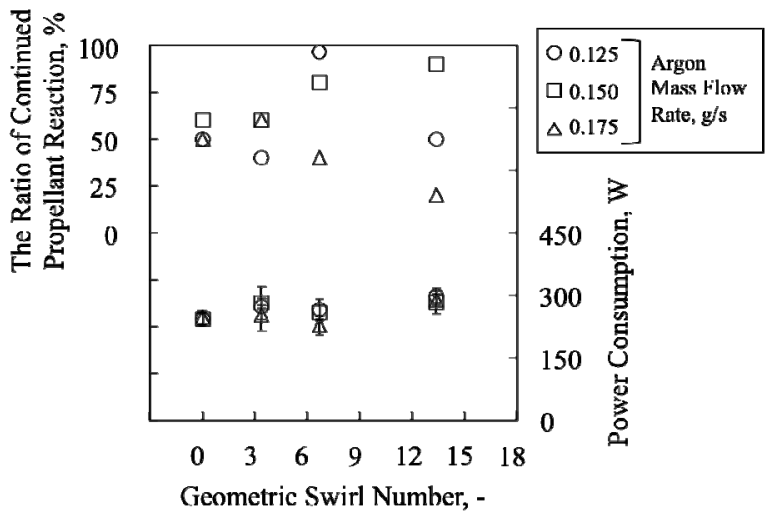

Fig. 7. Ratio of continued propellant reaction to the effects of geometric swirl number on the power consumption at Phase 3 .

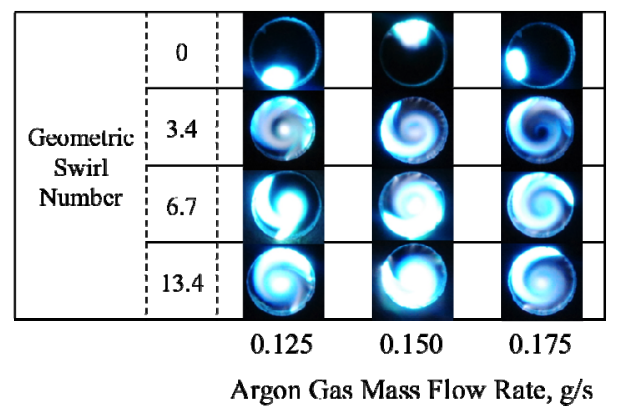

Fig. 8. Effects of the argon gas mass flow rate and geometric swirl number on the plasma distribution. These photographs were taken from downstream of the DPC-LM. (ISO: 800 , exposure time: $2.5 \mathrm{ms,}$ f: 20). section, the discharge plasma conditions, such as the distribution inside the discharge zone prior to supplying the propellant (Phase 2), are evaluated for the different experiments. The photographs shown in Fig. 8 were taken from downstream of the DPC-LM during Phase 2, and optimally taken from a single experiment. In addition, the plasma distribution randomly changed as a function of time, as shown in Fig. 9, and so were taken downstream of the DPC-LM during Phase 2 using a high-speed digital CCD camera (KATOKOKEN, K-II). It seems that the fullness of the discharge plasma increases as a function of geometric swirl number. At a geometric swirl number of 0 , the plasma is less distributed in the discharge zone, and changes location as a function of time. The lack of plasma distribution makes it difficult for the propellant to make contact with the plasma. However, in the case of a geometric swirl number of 0 , the

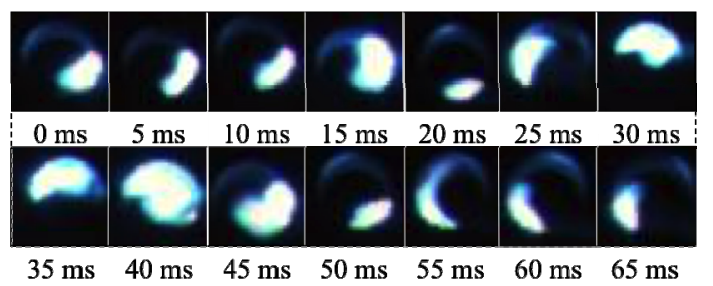

(a) Geometric Swirl Number 0

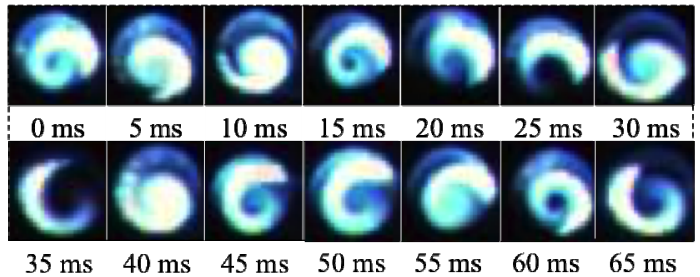

(b) Geometric Swirl Number 6.7

Fig. 9. Plasma distribution with geometric swirl number (a) 0 and (b) 6.7 at an argon gas mass flow rate of $0.150 \mathrm{~g} / \mathrm{s}$. These photographs were taken from downstream of the DPC-LM using a high-speed digital CCD camera (fps: 200, exposure time: $1 \mathrm{~ms}$ ).

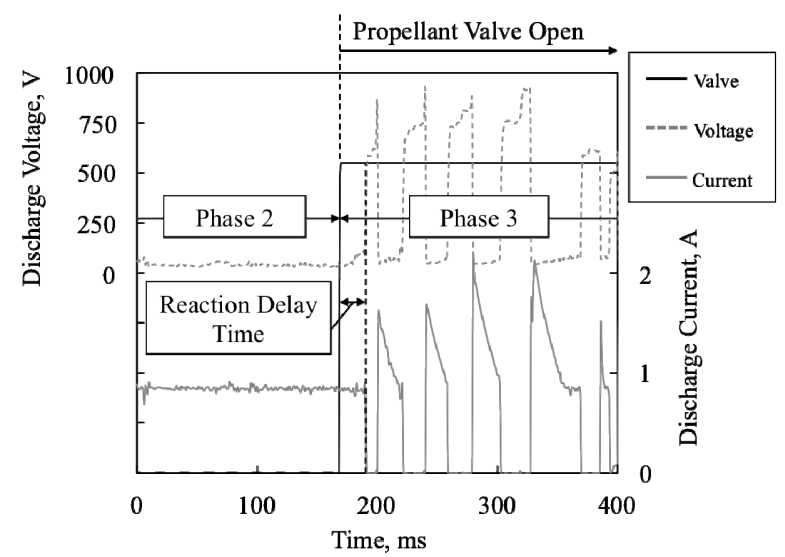

Fig. 10. Reaction delay time. The DPC-LM with a geometric swirl number of 6.7 , a propellant mass flow rate $0.3 \mathrm{~g} / \mathrm{s}$, and an argon gas mass flow rate of $0.125 \mathrm{~g} / \mathrm{s}$. 
propellant reaction is more stable than with a geometric swirl number of 3.4. It seems that the impingement of argon gas atomizes the propellant at the center hole of the swirl injector with a geometric swirl number of 0 , while the propellant at the geometric swirl number of 3.4 is less affected by the swirling argon gas. In addition, stable reaction has a non-negligible effect on the plasma distribution before propellant reaction. Thus, it seems that the propellant reaction is stabilized by the atomized propellant.

\subsection{Reaction delay time}

In this study, a reaction delay time (also known as ignition delay time) is defined as the time from the opening of the propellant valve to the start of the chemical reaction, as shown in Fig. 10. In this DPC-LM, when the propellant makes contact with the discharge plasma, the discharge voltage becomes higher. The discharge voltage fluctuates with changes in the electric resistance because the resistance of the mixture of the discharge plasma, the unreacted propellant, and the intermediate and combustion products is higher than the resistance of the discharge plasma. Thus, when the discharge voltage starts fluctuating, the propellant reaction has also started.

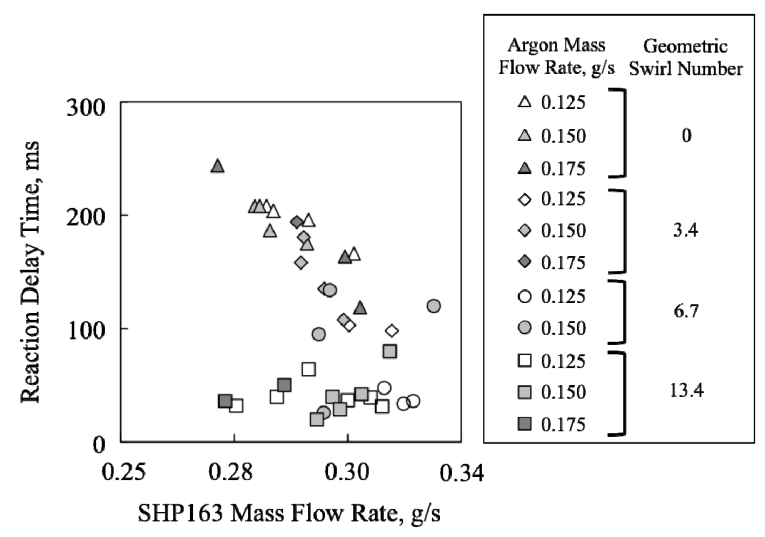

Fig. 11. Comparison between reaction delay times of each geometric swirl number.

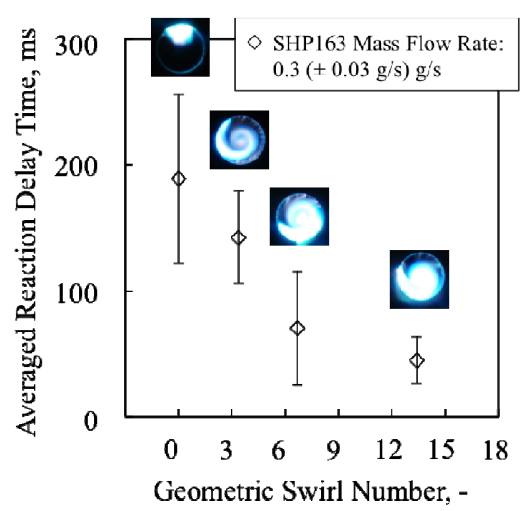

Fig. 12. Effect of the plasma distribution for each geometric swirl number on the averaged reaction delay time. These photographs of the plasma distribution were taken downstream of the DPC-LM for an argon gas mass flow rate of $0.150 \mathrm{~g} / \mathrm{s}$. (ISO: 800, exposure time: $2.5 \mathrm{~ms}$, f: 20$)$.
The measured delay times are shown in Fig. 11. It was confirmed that the delay time is less affected by the argon gas mass flow rate at each geometric swirl number. At a geometric swirl number of 0 , the delay time tends to be longer, e.g., more than $100 \mathrm{~ms}$. In contrast, at the highest geometric swirl number, the delay times are less than $100 \mathrm{~ms}$. It seems therefore that the plasma conditions inside the discharge zone have a non-negligible effect on the delay time.

The relation between the geometric swirl number and the averaged reaction delay time is shown in Fig. 12. The averaged delay time tends to be shorter at higher geometric swirl numbers. With the lack of plasma distribution at the lowest geometric swirl number, propellant has less contact with the discharge plasma; thus, the delay time may become longer.

\section{Conclusion}

To understand the propellant reaction characteristics of DPC-LM, the effects of geometric swirl number on the reaction characteristics were evaluated. It is concluded that the geometric swirl number has strong effects on the plasma distribution, the propellant reaction probability, and the reaction delay time. The continuity of the combustion flame was confirmed at an argon gas mass flow rate from 0.125 to $0.175 \mathrm{~g} / \mathrm{s}$ and SHP163 mass flow rate of $0.3 \mathrm{~g} / \mathrm{s}$. In addition, the effect of the geometric swirl number on the reaction delay time was confirmed, with higher geometric swirl numbers reducing the delay time.

\section{References}

1) Spores, R. A., Masse, R. K., Kimbrel, S., and McLean, C.: GPIM AF-M315E Propulsion System Development, $50^{\text {th }}$ AIAA/ASME/SAE/ASEE Joint Propulsion Conference \& Exhibit, 2014.

2) Gohardani, A. S., Stanojev, J., Demaire, A., Anflo, K., Persson, M., Wingborg, N., and Nilsson, C.: Green Space Propulsion: Opportunities and Prospects, Progress in Aerospace Sciences, 71 (2014), pp. 128-149.

3) Tanaka, N., Matsuo, T., Furukawa, K., Nishida, M., Suemori, S., and Yasutake, A.: The "Greening" of Spacecraft Reaction Control Systems, Mitsubishi Heavy Industries Technical Review, 48 (2011), p.44-50.

4) Amrousse, R., Katsumi, T., Itouyama, N., Azuma, N., Kagawa, H., Hatai, K., Ikeda, H., and Hori, K.: New HAN-Based Mixtures for Reaction Control System and Low Toxic Spacecraft Propulsion Subsystem: Thermal Decomposition and Possible Thruster Applications, Combustion and Flame, 162 (2015), pp.2686-2692.

5) Hatai, K., Nagata, T., Ikeda, H., Azuma, H., and Hori, K.: The Research and Development Activities on HAN-Based Monopropellant Thruster in JAXA, Space Propulsion Conference, 2014.

6) Sacheim, R. L., and Masse, R. K.: Green Propulsion Advancement: Challenging the Maturity of Monopropellant Hydrazine, Journal of Propulsion and Power, 30 (2014), pp.265-276.

7) Dinardi, A., and Persson, M.: High Performance Green Propulsion (HPGP): A Flight-Proven Capability and Cost Game-Changer for Small and Secondary Satellites, $26^{\text {th }}$ Annual AIAA/USU Conference on Small Satellites, SSC12-III-6, 2012.

8) Cardiff, E. H., Mulkey, H. W., and Bacha, C. E.: An Analysis of Green Propulsion Applied to NASA Missions, Space Propulsion 
Conference, 2014.

9) Fokema, M. D., and Torkelson, J. E.: Thermally Stable Catalyst and Process for The Decomposition of Liquid Propellants, U. S. Patent, US 20070184971.

10) Nagata, T., Masuda, I., Saitoh, N., Kajiwara, K., and Tahara, H.: Preliminary Design and Experiment for Gas Generator of HAN Based Propellant, JSASS-2012-4191, 57th Symposium on Space Science and Technology, 2012 (in Japanese).

11) Masse, R. K., Overly, J. A., Allen, M. Y., and Spores, R. A.: A New State-of-The-Art in AF-M315E Thruster Technologies, $48^{\text {th }}$ AIAA/ASME/SAE/ASEE Joint Propulsion Conference \& Exhibit, 2012.

12) Iizuka, T., Shindo, T., Wada, A., Kawabata, S., Sato, Y., Aoyagi, J., and Takegahara, H.: Basic Characteristics of Discharge
Plasma Ignition System for 1N-Class RCS Thruster with Green Monopropellant, Propulsion and Energy 2014, Cleveland, Ohio, USA, 28-30 July, 2014.

13) Wada, A., Iizuka, T., Shindo, T., Sato, Y., Kawabata, S., Aoyagi, J., and Takegahara, H.: Basic Characteristics of Discharge Plasma Ignition System for RCS Thruster with Green Propellant, Space Transportation Symposium, STCP-2013-063, 2014 (in Japanese).

14) Katsumi, A., Ideta, K., Ishibashi, T., and Tachibana, T.: One Newton Thruster by Plasma-Assisted Combustion of HAN-based Monopropellant, $48^{\text {th }}$ AIAA/ASME/SAE/ASEE Joint Propulsion Conference \& Exhibit, 2012.

15) Beer, J. M., and Chigier, N. A.: Combustion Aerodynamics, (1972), pp100-146. 